In two very helpful accounts of techniques, it is gratifying to find proper credit given to early workers: much recent writing seems to imply that the present-day solutions emerged fully-fledged within the past decade. Leftin and Hobson in "Application of Spectrophotometry to the Study of Catalyst Systems" (83 pp. and references 4 pp.) deal with optical absorption spectroscopy, applied to the investigation of some chemisorbed complexcs on metals, oxides and salts; coverage is complete but acid catalysts, espocially silica-aluminas, receive most attention as befits the interests of these authors and the pattern of previous reviews. Erlich's "Modern Methods in Surface Kinetics" (168 pp. and references $4 \mathrm{pp}$.) provides, in characteristic style, a thorough survey of flash desorption, field emission microscopy and ultra high vacuum technique (both methods and typical rosults) with a timely section on practical details. Fvidently these powerful tools, together with low-enorgy electron-diffraction, will soon be commonplace in research on clean metal surfaces. But when will the bridge between surface physics and surface chemistry be consolidated?

There are three contributions to the mainstream of catalysis, each in different voin. Mars, Scholten and Zwietering, in "The Catelytic Decomposition of Formic Acid" ( 75 pp. and references 4 pp.), survey present research and points of view concerning this model-reaction, about which discussion has sometimes reached polemic-force; dehydrogenation and dehydration over metals and oxides are discussed in detail and related to the water-gas shift raaction and the decomposition of bulk formates. The system is well suitod to tests of the intermediate compound theory of catalysis, but the authors are rightly guarded in their appraisal of recent generalizations. Catalysis in preparative organic chemistry is represented by the valuable, descriptive paper entitled "Tydrogenation of Pyridinos and Quinolines" (45 pp. and references 5 pp.) by Froifelder, which collects results obtained on the selective hydrogenation of these awkward, self-poisoning heterocyclos: one feels here the lack of a short section on mechanism designed to crystallize the topic. Margolis covers a wido and important field somowhat discursively in the chapter entitled "Catalytic Oxidation of Hydrocarbons" (68 pp. and references $5 \mathrm{pp}$.). The trend of Russian research emerges strongly, but strange phraseology obscures some passages, and vital points, such as the evidence for various forms of chemisorbed oxygen, are treated too lightly. There is a nice counterpoint between electron-transfor and chemical complex theories, but one is left wondering whethor sensitive surface-potential methods are central to the investigation of polyfunctional surfaces.

Calvin approaches the fundamental biochemical photocatalytic problem, in "Quantum Conversion in Chemplasts" ( $31 \mathrm{pp}$. and references $3 \mathrm{pp}$.), with the aid of photoconductive organic systems suggested by present organic semiconductor research, and draws some interesting parallels: it is exciting to see how the gap between the quick and the dead narrows.

In all, a well-composed medley-but surely the editor cannot still maintain that such diverse catalytic chemistry comprises a discipline "in its own right".

\section{A. DOWDEN}

\section{POPULAR PRESENTATION OF MEDICAL RESEARCH}

Our Most Interesting Diseases

By Harold Burn. Pp. 180. (London: George Allen and Unwin Ltd., 1964.) 25s.

(O) give to the lay public a description of the growing points of medical resmench to-dny is an important and urgent task. The difficulty that the writer has to overcome is one of communication: it is essential to exercise economy in the use of technical terms and to explain adequately and in simple language those that are used. Once again Prof. H. Burn has set himself this task and once again he has been successful. This book deserves to find many readers.

The topics that Prof. Burn has selected are all of great importance to those who live in a modern society. It is interesting that in his catalogue of our most interesting diseases the microbial infections are not listed. That they are omitted is a development that we owe to relatively recent successes in chemotherapy. The diseases that this book deals with are mainly those of late or middle age. Cancer, vascular and heart diseaso, gastric and duodenal ulcer, bronchitis-theso are topics that we find discussed.

In a book of this kind the reader cannot expect to find final or authoritative answers. The description of modern research is a tale of trial and error. The author's individual attitude must determine also how he selects and weighs the material discussed. What matters is that what is selected is adequately described, and that in each chapter the story has cohesion and adds up to give a clear picture of the present state of our knowledge. There are a number of instances where the reader would like to know if all the experts are in agreement with Prof. Burn's ovaluation of the evidence; but it is one of the great merits of this book that we are given the evidence and that we are allowed to arrive at our own conelusions.

Prof. Burn does not see medical science as a body of knowledge that is unrelated to our lives. The influence of environmont, of social conditions and habits on disease and health is discussed. Almost inevitably this leads in the final chapter of the book to a guide for healthier living. We are told to eat less, to drink less and to smoke less and not to give up physical exercise. These precepts are given with moderation and common sense; and this gives the author's injunctions both authority and authenticity.

H. BLASCHKO

\section{THEORY AND PRACTICE OF BIOLOGICAL CONTROL}

\section{Biological Control of Insect Pests and Weeds}

Edited by Paul DeBach. Pp. xxiv +844 . (London: Chapman and Hall, Ltd., 1964.) 120s.

P. CLAUSEN once remarked that insects are their (1. own worst enemies. Thoir other enemies include pathogenic micro-organisms, while their other victims includo plants. These ideas are well illustrated by numerous successes in the biological control of pests and weeds described in this book. Many of the suecesses have been in California. This is attributable partly to local ecological features, but also in grcat measure to a number of enthusiastic exponents of the method, notably to the leadership of the late Prof. Harry S. Smith, to whom the book is dedicated. Its 16 authors are all present or past staff members of the University of California, all specialists on the topics with which they deal, somo of them preeminont authorities. The outeome is a most impressive and comprehensive treatise, in which the advantages of multiple authorship have been fully exploited; thanks to careful planning and editing, tho disadvantages have, on the whole, been ovorcome. The subject is clearly and logically subdivided in a scheme fully set out in a contents list of 15 pagos.

In the first of the eight sections, P. DeBach deals with the scope of biological control and $R$. L. Doutt with its historical development. In Section. 2 , tho first 72 pages are devoted to an outline of the devclopment of population ecology, and to a discussion of ideas of natural control 